\title{
Ingenio artesanal y desviación comercial de las artesanías en el estado de Morelos*
}

\author{
PATRICIA MOCTEZUMA YANO**
}

\begin{abstract}
Artisan Talent and Commercial Deviation of Crafts in the State of Morelos. This comparative analysis of two craft traditions of the state of Morelos examines the organizational consequences that happen when modifying the value of use of crafts in order to satisfy tourist demands. This commercial deviation has implied multiple changes. The article focuses in the cultural aspects that constrain the development of craftsmanship and its role in cultural consumption through the continuity of a crafts tradition, and how this renders a different light on the labor among new generations.
\end{abstract}

Key words: tourism, patriarchal family model, cultural patrimony, labor inheritance

\begin{abstract}
Resumen
El presente análisis comparativo de dos tradiciones artesanas del estado de Morelos examina las consecuencias organizativas que ocurren al modificar el valor de uso de una artesanía para satisfacer la demanda del turismo. Esta desviación mercantil ha implicado múltiples cambios. El artículo se enfoca en los aspectos culturales que constriñen el desarrollo artesanal, en el papel que ejerce el consumo cultural en la continuidad de una tradición artesana y en cómo esto lleva a una valoración distinta del oficio entre las nuevas generaciones.
\end{abstract}

Palabras clave: turismo, modelo familiar patriarcal, patrimonio cultural, herencia laboral

\section{Introducción}

$\mathrm{P}$ ara la antropología, la cultura material es una expresión y mediación de las relaciones sociales humanas y nos permite conocer los criterios culturales que subyacen en la herencia social. El presente análisis comparativo entre dos tradiciones artesanas del estado de Morelos nos muestra cómo un cambio en el valor de uso de las artesanías ha conllevado una compleja transición del oficio mismo.

Con el fin de contribuir a la tendencia que registran muchas tradiciones artesanales de México, ${ }^{1}$ en este artículo analizo lo que para ellas significa la desviación comercial. Una producción artesanal puede ser pasajera o bien anclarse históricamente y cristalizar en una tradición, para que el conocimiento vertido que la caracteriza pase de una generación a otra. No obstante, las tradiciones no son estáticas y a lo largo del tiempo precisan

\footnotetext{
* Artículo recibido el 30/08/17 y aceptado el 14/02/18.

** Universidad Autónoma del Estado de Morelos, Centro de Investigación Interdisciplinar en Humanidades. Av. Universidad núm. 1001, col. Chamilpa, 62209, Cuernavaca, Morelos, México <moctezumapaty@hotmail.com>.

1 Metodológicamente para recopilar la información apliqué entrevista dirigida, así como historia de vida laboral, tanto del artesano como de su taller. El análisis lo llevé a cabo durante mi estancia de sabático del Centro de Estudios Arqueológicos del Colegio de Michoacán, sede la Piedad, en la línea de investigación "Tradiciones ocupacionales y saberes tradicionales: artesanías y arte popular”.
} 
irse modificando en sus funciones y significados; por ello, reviso aquí la actualización de dos distintos tipos de oficios artesanos que reinventan su tradición para mantenerse vigentes.

Estos procesos de adecuación artesanal evidencian la capacidad de los artesanos -invención organizativa, creatividad técnica y apertura comercial- de diseñar artículos atractivos para el turismo. Este talento para, una y otra vez, adaptar su oficio al contexto cuestiona la visión folclorista de buscar la conservación de las tradiciones como si por naturaleza fueran estáticas (Ramírez Garayzar, 2014: 196), en un afán por preservar su autenticidad, entendida ésta como su correspondencia a cierta época pretérita. La autenticidad es una cualidad que actores o instituciones, con motivos comerciales, históricos o políticos, entre otros, asignan a objetos artesanales para dignificarlos como patrimonio cultural y que, por lo tanto, los convierten en obras importantes de salvaguardar.

Esta rígida concepción de las tradiciones artesanas desdibuja el papel del artesano e impide visualizar las estrategias que instrumentaliza para tener al día su producción; es decir, se trata de una postura inflexible frente a innovaciones técnicas, comerciales y organizativas que los artesanos precisan implementar para mantener vigente la demanda de sus artículos, incluso por encima de la estimación que puedan tener de su saber artesano.

Así, expondremos la necesidad de los artesanos de innovar su producción y ventas para el turismo; aunque, curiosamente, para lograrlo hayan mantenido el modelo familiar patriarcal como la infraestructura básica para la organización del trabajo; modelo ancestral que favoreció la génesis del trabajo colectivo (entre éste las artesanías) y el sedentarismo (Sennett, 2009: 17-22). ${ }^{2}$

Aunque en esencia se conservó esta forma organizativa, cabe destacar que en Tlayacapan, en la transición de producir loza a cerámica decorativa la autoridad no recayó necesariamente en la figura paterna ni en la interdependencia entre parientes; de hecho, se propició la independencia de los talleres de los hijos, como veremos en detalle.

A partir de 2013, cuando gracias a diversos atractivos -arquitectura, tradiciones, danzas, festividades religiosas, tradición culinaria, alfarería, entre otrosse asignó a Tlayacapan el nombramiento de pueblo mágico, se incrementó el turismo, favorecido además por la construcción de carreteras y el incremento de balnearios, restaurants, museos y hoteles; lo que trajo consigo la disminución de la producción de loza tradicional. Nos preguntamos ¿cómo entienden las nuevas generaciones de artesanos este cambio?, ¿cuáles son las ventajas productivas y comerciales que encierra la producción de suvenires para el turismo?

Contrastaremos este caso con el de los productores de jaulas del ejido de Palo Alto, Tlaltizapán, sitio carente de atractivos turísticos, pero donde crecen tanto el carrizo para la elaboración de canastos como árboles cacaloxóchitl para la confección de jaulas para la cría de animales y que ahora se decoran para vender a los turistas como objetos suntuarios. Con base en esta perspectiva comparativa, la presente etnografía tiene el propósito de contribuir al análisis de las múltiples transiciones que en la actualidad experimentan las tradiciones artesanas del país y, en particular, las adecuaciones del modelo familiar patriarcal en cuanto infraestructura organizacional del trabajo.

\section{Desviación comercial y tradición artesanal}

Veamos con detenimiento las consecuencias del giro productivo de artesanías de uso cotidiano a artículos decorativos y cómo sus artesanos entienden las implicaciones comerciales.

Para los alfareros de Tlayacapan este proceso ha conllevado múltiples cambios, pero resalta el desinterés de los jóvenes por conservar los conocimientos (técnicas, destrezas, manejo de moldes y otras herramientas), empleados en la manufactura y cocción de la loza tradicional, es decir, de cazos y cazuelas de gran tamaño usados para cocinar banquetes en diferentes festividades, las cuales promueven la cohesión social en diferentes grados de integración sociocultural: barrio, capilla, pueblo, instancias espaciales, en donde tienen lugar prácticas culturales que nutren la identidad y la pertenencia social. ¿Será posible que una tradición alfarera tan legendaria se vea desmantelada por la momentánea demanda del turismo de objetos cerámicos "suvenires"?

En cambio, el caso de las jaulas de Palo Alto revela cómo la presencia de este nuevo consumidor, el turista, brinda un nuevo aliento y sentido productivo y comercial a una artesanía que de no ser por este giro hubiera sido abandonada, porque su valor de uso sucumbió, pues disminuyó la cría de animales

2 Sennett revisa la génesis del taller familiar artesano desde la época de la Grecia antigua y retoma el himno a Hefesto, el patrón de los artesanos, donde se recuerda que para sacar al hombre de las cavernas y favorecer el desarrollo del sedentarismo fue indispensable trabajar en colectivo, partiendo del padre y sus hijos para la elaboración de artefactos de uso cotidiano tales como los de la alfarería. 
de corral como actividad económica significativa en el ámbito rural.

La jaula no era objeto artesanal, pero pasó a serlo; no se suscitó cambio alguno en su proceso de elaboración y sólo se le añadió la fase del decorado. ¿Será que el turismo como consumidor puede llegar a ser tan importante al grado de llevar a una tradición artesana a transformar el uso consuetudinario de sus creaciones? ¿El sector consumidor se convertirá en la condición más primaria en la continuidad de los oficios artesanos? ¿No es esto una forma muy mercantilista de valorar las tradiciones artesanales, omitiendo el papel que tiene el artesano en la continuidad de un oficio?

Estas y otras preguntas nos permitirán analizar la transición del valor de uso de las artesanías por la demanda del turismo, con miras a esclarecer posibles tendencias de cómo se preservarán los oficios artesanos a futuro. En lo que respecta a las comunidades de estudio, veremos que en ambas decayó la agricultura de subsistencia, misma que solía guardar una estrecha relación complementaria con la artesanía, a lo que se aúna la explosión demográfica y los cambios en la ley agraria de 1992, los cuales han llevado a un nuevo escenario a las sociedades campesinas del país (Arias, 2009).

A la par, se registra en toda la república un acelerado proceso de urbanización, que ha acortado la distancia cultural y física de los pueblos campesinos y favorecido la movilidad, acrecentando las posibilidades educativas y ocupacionales de los jóvenes, incluyendo la opción de migrar al vecino país en búsqueda de horizontes laborales distintos.

Cambios como éstos han generado una ideología que separa a los jóvenes de sus padres y abuelos, y por lo mismo tienen una distinta valoración de la artesanía, la cual, por su parte, no necesariamente garantiza la reproducción socioeconómica de los grupos domésticos. ${ }^{3}$ Hoy en día los jóvenes se cuestionan la residencia patrilocal posmarital, la cual, como veremos, nutre sustancialmente la socialización del individuo en cuanto artesano; lo que ahora prefieren es la residencia neolocal y con ello se dificulta la enseñanza del oficio. Estas y otras transformaciones ideológicas en torno al modelo familiar patriarcal como base estructural de la organización del trabajo artesanal ponen al descubierto el tipo de adecuaciones que observan los oficios artesanos para mantenerse vigentes. Vayamos entonces a conocer algunas características de dicho modelo.

\section{Principios organizativos del quehacer artesanal}

En la Nueva España, las tradiciones de los oficios tuvieron un papel importante en la historia fundacional; destrezas y conocimientos artesanales de tiempos prehispánicos se fusionaron con aquellos traídos por los españoles, dando por resultado un fructífero intercambio, que en la actualidad consagra a México como país artesano.

Por costumbre, el oficio artesano se identifica como un saber doméstico, porque se realiza en el espacio del hogar y se utiliza básicamente mano de obra familiar, la cual va cambiando de acuerdo con la composición sociodemográfica, esto es, cantidad y cualidad genérica de mano de obra, en cada etapa del ciclo vital.

La socialización del sujeto como artesano empieza desde la tierna infancia, cuando el pequeño se va familiarizando con la rutina de tareas artesanales que se entrelazan con las actividades domésticas y es difícil desvincularlas. Digamos que a los seis años un niño ya conoce, aunque no domine todavía, los materiales y el uso de herramientas empleadas en cada tarea, y está compenetrado con todo el proceso productivo.

Se considera también que las artesanías son oficios domésticos porque la organización del trabajo descansa en la estructura que provee la familia, como los ejemplos aquí investigados, en donde el varón cumple un papel protagónico como maestro y jefe del taller, y la mujer figura sólo en cuanto cónyuge; de ahí que el prestigio de los dominios artesanales recaiga de manera principal en el hombre, y aun cuando la mujer participa en la producción, su labor es poco o nada reconocida.

El modelo familiar patriarcal descansa en tres principios organizativos. Uno de ellos es el de la descendencia, que se traza de manera unilineal por vía masculina, esto es, por vía paterna. Los miembros integrantes de un patrilinaje reconocen un ancestro en común y su pertenencia al linaje les brinda derechos y prerrogativas; así, por ejemplo, el hijo de un artesano tiene el derecho de aprender el oficio y el padre está obligado a enseñárselo y, en retribución, cuando el hijo sea mayor y tenga su propio taller, se verá obligado a mantener a su padre. Si ocurriera que sigue trabajando, entonces el hijo tendrá que apoyarlo siempre en diversas tareas: acarrear y amasar el barro o edificar un horno, pues son labores que por la edad se van dificultando a los mayores.

3 De hecho, en el ámbito rural se propende hacia la unión libre como opción conyugal, las disoluciones matrimoniales son más frecuentes y la tendencia es que las parejas tengan menos hijos; estos factores han favorecido la opción de ser madre soltera y con ello los hogares monoparentales encabezados por una mujer (Arias, 2009). 
Asociado a esta pauta de descendencia patrilineal tenemos que la residencia posmarital suele ser patrilocal; esto es que cuando un hijo se casa o se une lleva a vivir a su esposa al recinto doméstico que le provee su padre, residencia que dejará para conformar su propia vivienda y taller después de unos años, cuando se independice del taller paterno.

El tercer principio es el de la sucesión, ya sea de bienes tangibles (cuando el padre, en vida o muerto, deja a sus hijos herramientas de trabajo como un horno $u$ otro terreno), o intangibles (todos los secretos técnicos y organizativos para ser un artesano exitoso). De proseguir la migración de los jóvenes a Estados Unidos y la dificultad de heredar tierras a los hijos, este tercer elemento es el más endeble de todos y cuestiona la continuidad del oficio.

Por último, habría que agregar un anexo normativo a los tres criterios mencionados: el principio agnaticio, a través del cual los parientes consanguíneos que trazan su descendencia por vía paterna conforman un grupo social: el agnado (conformado por los hijos varones del padre, o sea, por los hermanos).

Bajo este principio agnaticio-que veces se extiende a otros vínculos de parentesco colaterales como tíos o primos, o bien a parientes rituales digamos cuñados o yernos-, los varones constituyen un grupo social que opera bajo un principio de reciprocidad para desempeñar diferentes prácticas culturales -participar en las mayordomías de los cargos religiosos y en las comparsas dancísticas- o para realizar tareas diversas, ya sea en el campo o precisamente en el taller artesanal; de hecho, este principio agnaticio juega un papel preponderante en la génesis y consolidación de un taller artesano (Moctezuma, 2010).

En Tlayacapan y Palo Alto se guarda en común el modelo familiar patriarcal como base organizativa del trabajo artesanal, pero no se implementaron nuevas técnicas de elaboración, sino que con los mismos conocimientos se ha dado un nuevo acabado a las mercancías, para lo cual se introdujeron nuevos materiales y herramientas de trabajo, haciendo posible la producción de objetos atractivos para el turismo.

Estas estrategias productivas y comerciales dan cuenta de la capacidad de los artesanos para actualizar su oficio, lo cual pone de manifiesto que la artesanía ahora busca, en primer lugar, generar ingresos, y ya no se enfoca en suministrar artículos de uso cotidiano para el autoconsumo.
Lo anterior, de alguna manera indica una modificación en la forma de valorar los oficios artesanos y, sobre todo, cuestiona, del modo en que Hegel señaló, una de las aserciones que distinguen el arte (como forma espiritual de la autoconciencia de los pueblos) de las artesanías (como aquellas manifestaciones artísticas gestadas desde la quietud que alcanza la vida social).

...y las artesanías son formas pre-artísticas enraizadas en la quietud de la autoconciencia, esto es en el modo histórico de las sociedades y se vuelven autorreferenciales y que por lo tanto no pueden desatar ya ninguna transformación que no esté de antemano codificada en la lentitud de la imagen enajenada de sí... [Oliva, 2009: 289].

Pero recordemos que el valor de uso de una artesanía no es un valor menor, es aquel que lo distingue del arte y expresa el ingenio colectivo de un pueblo en un momento histórico, contexto territorial y étnico (Sennett, 2009). Aunque, claro está, hay expresiones dentro de las artesanías que se consideran arte popular, y si bien hay diferencias en cuanto a su definición (Rubín de la Borbolla, 1971: 17; Kaplan, 1980; Novelo, 1996; Narosky, 1988; Bartra, 2004), en lo fundamental son artesanías únicas en las cuales se reconoce la autoría del artesano que utiliza de forma específica el legado técnico para su confección, mismo que se resguarda como patrimonio familiar y se transmite básicamente de padres a hijos.

Mas la cerámica decorativa y las jaulas de nuestro análisis no son expresiones de arte popular y, como no expresan una función pragmática para sus creadores y carecen de esta valoración, es más factible que no sean perdurables o, como señala Oliva:

Así el trabajador artesanal genera objetos necesarios para la comunidad, y de forma secundaria, vacía los aspectos centrales de la cultura en su obra... [Oliva, 2009: 291].

Esto se corrobora muy bien en el caso de la loza de Tlayacapan, ${ }^{4}$ porque los enseres de cocina juegan un papel central en la tradición culinaria festiva y, si partimos del hecho de que la alfarería como artesanía se distingue de otras porque se asocia a una de las necesidades fisiológicas más básicas del ser humano: la alimentación, es una artesanía universal en la humanidad, y la pérdida de esta loza implica el olvido del

4 En el trabajo de campo en Tlayacapan primero se realizaron entrevistas generales a las familias de alfareros para introducirnos a los aspectos sociotécnicos de la producción. A continuación, se seleccionaron 20 talleres familiares, teniendo en cuenta que al menos dos generaciones atrás se hubieran dedicado a los enseres de gran tamaño; y, por último, de esa muestra se escogieron siete alfareros cuya historia laboral nos revelara las adecuaciones que han puesto en práctica para mantenerse vigentes en este género cerámico, tomando en consideración factores micro- y macroestructurales. 
conocimiento a través del cual los seres humanos (a lo largo de su historia), culturalmente y en un hábitat específico, eligieron ciertos alimentos para cubrir determinadas expectativas acordes a su contexto histórico; esto quiere decir que la desaparición de esta artesanía conllevará borrar de la memoria información implícita en la estética culinaria campesina, a través de la cual se pueden dilucidar otras pertenencias culturales, valores, significados y sentidos sociales.

Así, vemos cómo en la elaboración de banquetes en Tlayacapan, ${ }^{5}$ para distintas celebraciones profanas ${ }^{6} y$ religiosas, los actores instrumentalizan una dimensión lúdica, es decir, una oportunidad recreativa para convivir. Preparar alimentos de manera colectiva requiere una división de tareas por género y habilidades personales -los hombres cargan los recipientes y hacen los fogones y las mujeres despliegan sus conocimientos como guisanderas- y su desempeño retribuye en su prestigio social; pues al estar guisando la gente está platicando y se hacen chistes o comentarios descalificativos, aludiendo a algún episodio de su vida donde se recrea la pertenencia social, de género, de oficio, de época, de parentesco... Además, en este contexto de sociedad campesina, participando en la elaboración de banquetes, las personas pueden poner de relieve su capacidad de compromiso, reciprocidad, intercambio, bonanza; acciones que culturalmente fortalecen los lazos que sustentan una compleja red de relaciones sociales.

Cabe destacar que la estética culinaria campesina donde se ocupa esta loza se extiende en todo el estado de Morelos y estados vecinos-Puebla, Estado de México y Tlaxcala- y, pese a la demanda, este género cerámico corre el riesgo de ser desplazado por recipientes de origen industrial; propensión intensificada por la explosión productiva de cerámica decorativa.

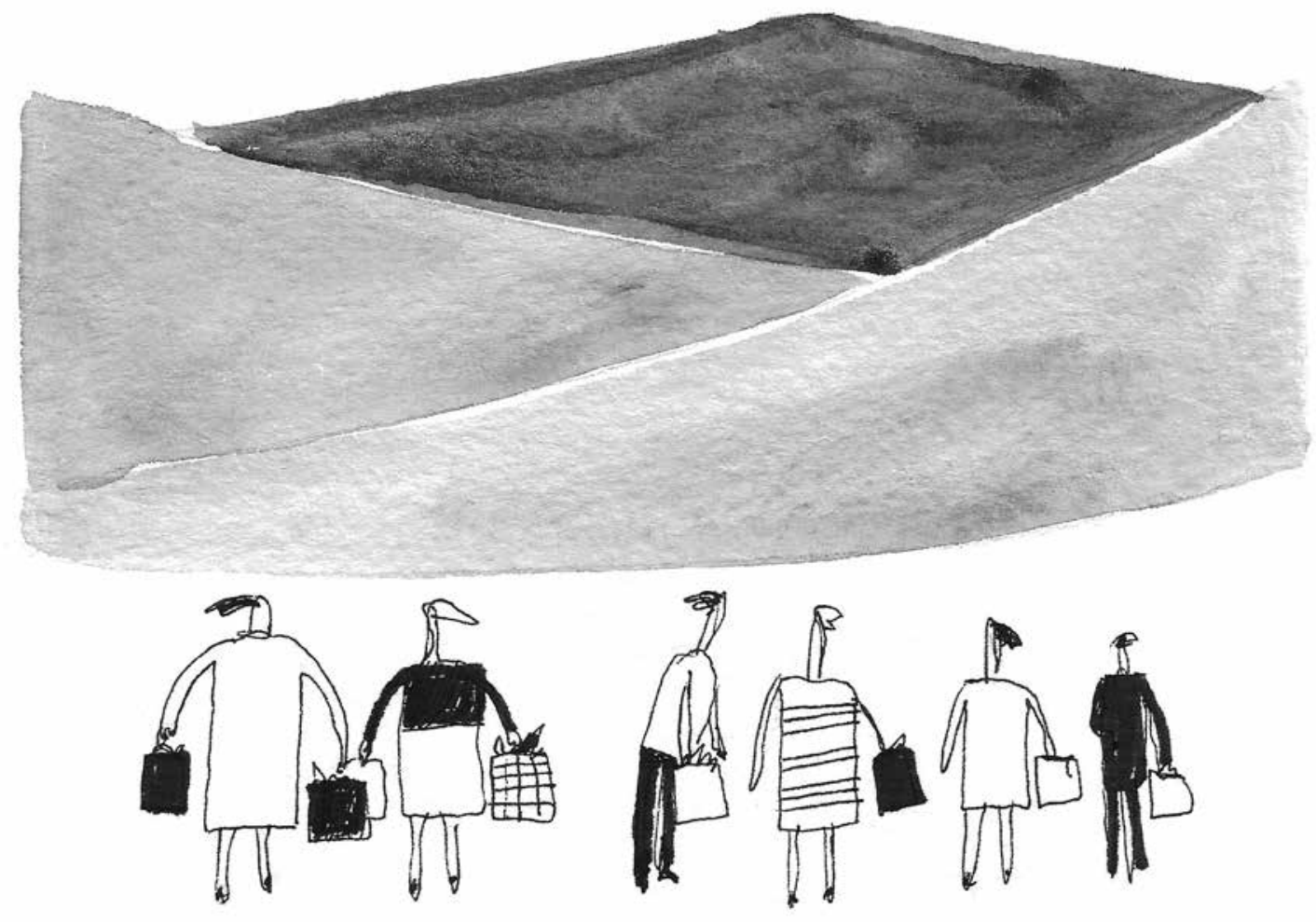

5 La loza utilitaria que guarda una relación complementaria con la cerámica ritual esmaltada en negro que se trabaja para decorar los altares que conmemoran la celebración de los fieles difuntos, $1^{\circ}$ y 2 de noviembre, que incluye candelabros e incensarios, así como ollas, jarros y cazuelas chicas y medianas (todos esmaltados en color negro). También la cerámica conocida como figuras de ornato y, una más, la que propiamente está en peligro de extinción y que representa figuras -zoomorfas y antropomorfas- bañadas en cal blanca y decorada en vistosos colores, que solían utilizarse durante las terapias curativas de enfermedades espirituales de sesgo mesoamericano (Moctezuma, 2015).

6 Relativas al ciclo vital reproductivo como bodas, bautizos, fiestas de primera comunión, o bien al ciclo ritual católico: mayordomías de 32 capillas y un santuario. 
Son muchas las pérdidas culturales asociadas a la disminución de los alfareros productores de cazos y cazuelas, y con ello estamos ejemplificando cómo se desdibujará el papel histórico que tuvo la alfarería en la transición de la sociedad de cazadores y recolectores a aldeas de cultivadores, o sea al sedentarismo; como bien lo atestigua el himno homérico de Hefesto, el patrón de los artesanos en la antigua Grecia: "la artesanía sacó a la gente del aislamiento porque obligó a la gente a trabajar en colectivo". En esa época, para designar a un artesano se utilizaba el término demioergos: de demios público y ergon productivo (Sennett, 2009: 18); y, como bien se sabe, la alfarería, en sus distintas modalidades, ha sido una de las mayores artes en el proceso de la civilización (Lévi-Strauss, 1986: 18).

Incluso, según la etnoarqueología, era tan necesario disponer de enseres, que aquellos pueblos de la Antigüedad que no tenían vetas de barro cercanas se desplazaban largas distancias para conseguirlo; su carencia favoreció la presencia de circuitos comerciales de pueblos que sí poseían barro y lo intercambiaban por algún otro bien (Dean, 1985). Ejemplifiquemos a continuación esta transición para mirar con detenimiento las posibles consecuencias.

\section{El taller de los hermanos Salazar: "De la cazuela a la maceta bonsái sólo hay un paso"}

Felipe Salazar y Feliciana Santamaría crecieron entre ollas y cultivos de maíz y frijol. Como cualquier niño en el pueblo ayudaban a las tareas del campo y de la cerámica desde muy temprana edad. Una de sus diversiones era ir con sus padres a llevar loza a los tianguis de la región, porque además de ser paseo a caballo podían comprar productos de otros sitios -fruta, dulces, quesos- y si la venta era buena había la posibilidad de hacerse de alguna prenda o juguete.

Los varones se dedicaban a hacer enseres grandes -cazos y cazuelas-, porque hace falta fuerza para manejar los pesados moldes, así como cargar y descargar de leña el horno, además, como la técnica de elaboración de los cazos grandes es muy compleja, requería dedicación de tiempo completo. En cambio, las mujeres hacían loza chica y mediana, la de uso cotidiano, porque requiere de menos fuerza y tiempo, tomando en cuenta que la crianza y las labores domésticas demandan mucha atención, entonces esta loza fue la especialización femenina de tiempo parcial.

Foto 1

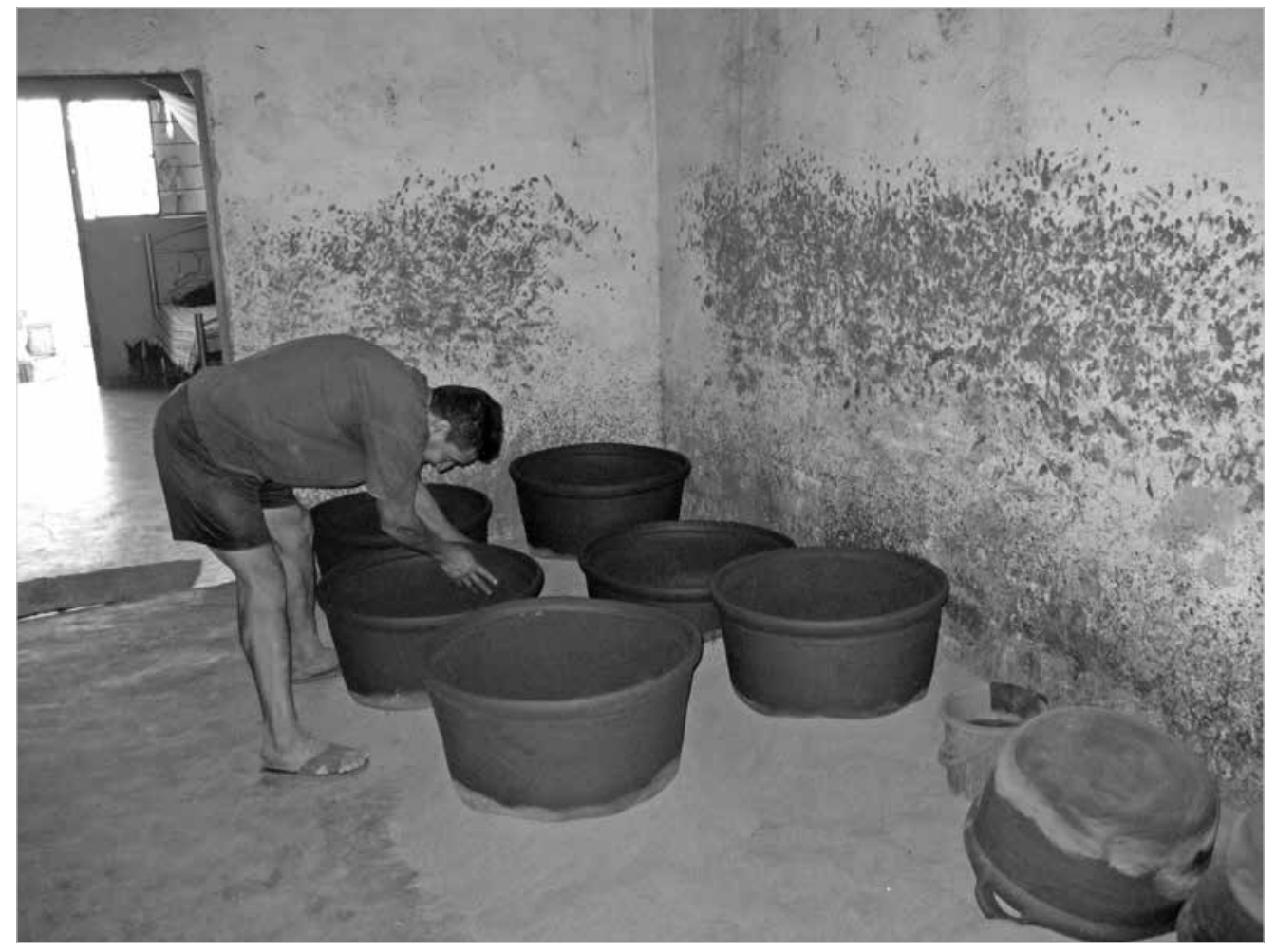

Productor de loza tradicional, Tlayacapan 


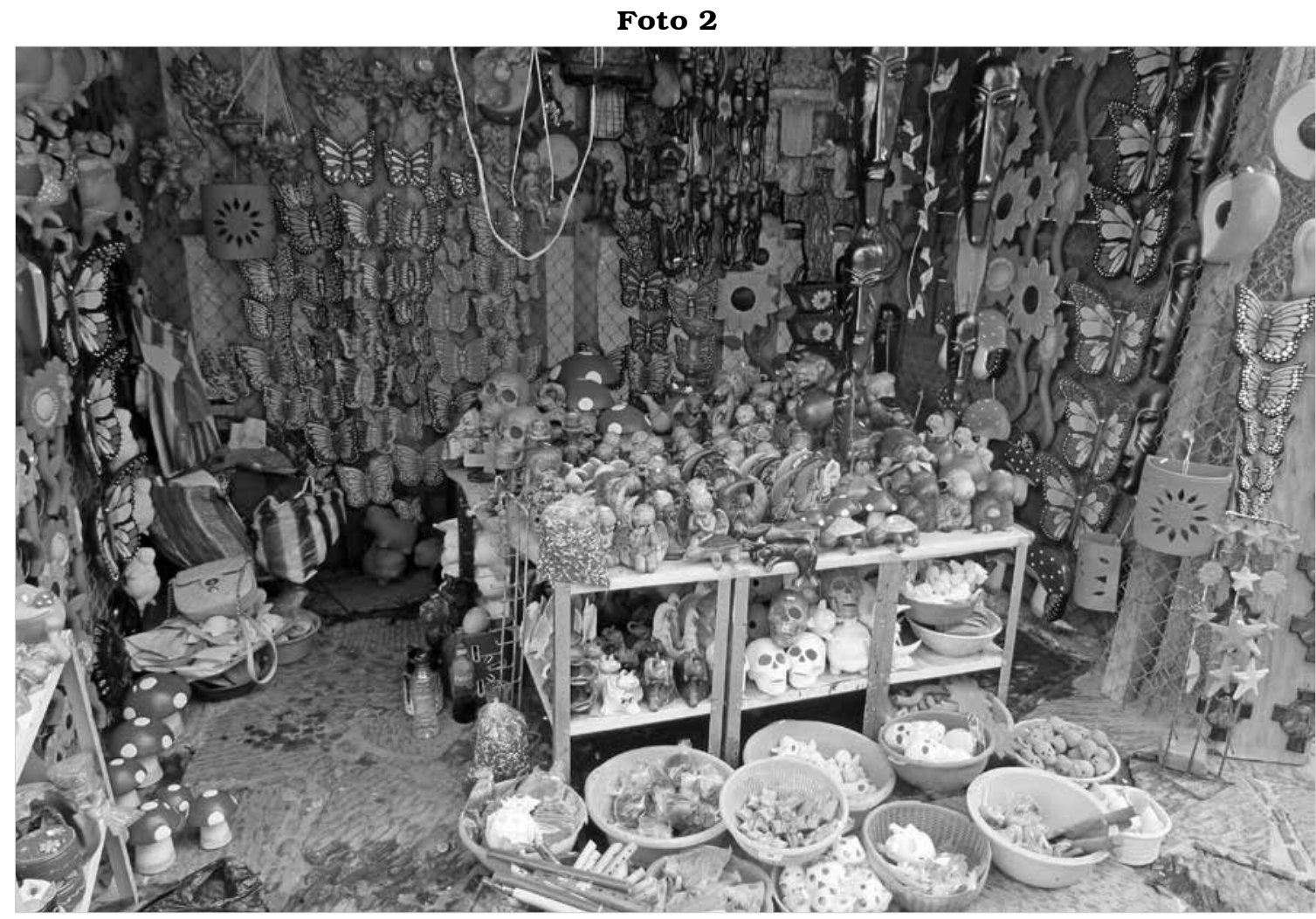

Local de venta de figuras decorativas, Tlayacapan

Felipe y Feliciana se conocían desde niños, se enamoraron y se casaron. Siguiendo la costumbre de la residencia patrilocal, ella se trasladó a vivir a casa de sus suegros, donde, ya casado, su marido siguió trabajando varios años en el taller paterno. Después, cuando ya tenían ocho años de casados y cuatro hijos, Felipe recibió de su padre un terreno contiguo a la casa de éste, donde edificó su casa, taller y horno.

Pasó el tiempo y él y sus hijos hacían enseres grandes a lo largo de todo el año, mientras las mujeres en casa, Feliciana y sus cuatro hijas, elaboraban utensilios chicos y medianos de enero a agosto; a partir de septiembre se concentraban sólo en la producción de candelabros y copaleros, que los hombres esmaltaban en negro para ser utilizados en las ofrendas de Todos Santos. ${ }^{7}$ En ese entonces llevaban sus mercancías a vender a los tianguis semanales de la región: Ocuituco, Yecapixtla, Yautepec, Atlatlahucan y Cuautla, donde era usual el trueque por productos de consumo de la región: queso, cecina, fruta, dulces, muebles, textiles.

Así, sobrevino la etapa en que todos los hijos eran adolescentes y podían trabajar en el taller, fue la épo- ca más productiva de los cazos, pues contaban con abundante mano de obra familiar masculina. Luego, estos muchachos se empezaron a casar y, por la residencia patrilocal, llegaron a casa cuatro nueras. Si bien a cada uno lo apoyaron para mantener la alfarería, muchos aspectos cuestionaron este seguimiento. En la década de los setenta, entre los jóvenes se acrecentó la búsqueda de ingresos mediante la migración $\mathrm{y}$, por la construcción de la carretera, el transporte se agilizó y con ello la posibilidad de salir a estudiar fuera del pueblo, además de la aparición de acaparadores interesados en el comercio de esta clase de artesanía.

En este contexto, un buen día llegó un intermediario de plantas a casa de los hermanos Salazar. Observó el aspecto de la cazuela y les propuso que, conservando el diseño de la misma, la adecuaran para hacer macetas de paredes bajas, propias para sembrar árboles bonsái y cactáceas. Tentados por la oferta, Felipe y sus hijos experimentaron la manufactura de estas macetas y lo lograron exitosamente.

Hoy en día tienen pedidos, no sólo de este intermediario sino de varios dueños de viveros de Cuautla y Yautepec. De este modo, poco a poco Felipe y sus hijos

\footnotetext{
7 La loza esmaltada lleva dos cocciones, primero se quema la pieza a una temperatura que alcanza casi los $800{ }^{\circ} \mathrm{C}$; ya fría se hace la segunda quema, o derretida, a $600{ }^{\circ} \mathrm{C}$ y de menor duración, por todo esto, la loza esmaltada implica más trabajo, tiempo y costo de producción, ya que el material para el esmaltado sube de precio constantemente.
} 
se especializaron en la maceta "bonsayera", y ahora sólo bajo pedido hacen enseres de gran tamaño. El cuarto hijo de Felipe, Ángel, quien estudió algo de electricidad en el Colegio Nacional de Educación Profesional Técnica (Conalep), implementó sus conocimientos para hacer fuentes, articulando varias macetas bonsái entre sí, electrificó la fuente simulando el ir y venir del agua, fuentes que hoy en día se venden muy bien al turista.

Ahora Ángel y su esposa, con sus hijos adolescentes, trabajan en su propio taller, que construyeron en el pedazo de tierra que le heredó Felipe. Comparte con él y sus hermanos el horno grande, y para las piezas chicas edificó un horno pequeño. Para completar los ingresos de la maceta bonsái, Ángel y su familia elaboran objetos cerámicos decorativos, los pintan y venden los fines de semana a los turistas por menudeo y a mayoreo a los intermediarios; de las ganancias percibidas pagan la colegiatura de sus hijos y con lo de las macetas se mantienen e invierten en gastos del taller.

De esta manera vemos cómo la estrategia de no trabajar un solo tipo cerámico les ha permitido salir adelante, y con ventajas adicionales, porque si hacen únicamente cazos y cazuelas necesitan mucho espacio y se venden lento, lo que contrarrestan complementando su producción con la manufactura de la figura decorativa, que requiere menos espacio para orearse y se realiza más rápido.

Esta misma práctica, en distintas modalidades, la han seguido los tres hermanos de Ángel y, por ende, los nietos de Felipe no dominan técnicamente del todo las fases del proceso de elaboración de los cazos y cazuelas grandes. Este cambio productivo es una tendencia favorecida además por la reventa de figuras de yeso y barro que revendedores compran en los talleres circunvecinos a la ciudad de Cuernavaca -colonia la Joya y la Independencia- y quienes llegan los fines de semana a surtir a los alfareros de Tlayacapan, lo mismo que los vecinos de San Bartolo Cohuecán, que ofrecen piezas de barro que sólo deben ser pintadas y están listas para su venta; esto es, los jóvenes que se dicen alfareros en realidad son decoradores y comerciantes de cerámica suntuaria.

Siguiendo estas estrategias han aumentado los talleres dedicados a decorar figuras. Es usual que se contrate para pintar, con salarios muy bajos, mano de obra femenina. No se les brinda protección alguna para contrarrestar las substancias tóxicas de las pin- turas y esmaltes, y las trabajadoras están sujetas a jornadas muy largas, además de que tienen una alta probabilidad de ser despedidas por cualquier incidente, o bien son contratadas temporalmente.

Esta forma de proceder aumenta día a día y queda de manifiesto en la aparición de locales comerciales en manos de jóvenes cuyos padres o abuelos fueron productores de loza. En estas tiendas se venden dichas figuras decorativas y otros artículos artesanales -ropa, joyería, ceras, lámparas de cartón o papel maché- procedentes de otras partes de México e incluso de países como: Indonesia, China y la India, mercancías que se ofrecen a menudeo a los turistas y a medio mayoreo a intermediarios. Estas y otras implicaciones sociotécnicas y laborales ha traído consigo la desviación productiva y comercial, veamos cómo se contrasta este caso con el de las jaulas de Palo Alto, Tlaltizapán.

\section{Palo Alto: de jaula de corral a jaula decorativa}

A diferencia de lo que ocurre en Tlayacapan, en el caso del cambio de valor de uso en las jaulas de Palo Alto, las implicaciones de esta transición no han tenido efectos tan drásticos; de hecho, la técnica de elaboración se mantuvo, sólo se aplicó una fase sencilla de decorado y se implementaron nuevos diseños de las jaulas. ${ }^{8}$

Cierto es que este cambio de uso pone en evidencia que la importancia de la cría de animales de corral en el ámbito rural ha disminuido, mas, en otro sentido, deja muy claro que las artesanías a veces precisan salir de su anclaje cultural -étnico, cultural, socioeconómico y territorial- para vislumbrar un nuevo horizonte comercial y preservarse como opción laboral que pueda seguir cumpliendo la función de generar ingresos para contribuir a la reproducción de los grupos domésticos campesinos.

La jarciería, en la que se inscribe la producción de jaulas que emplea fibras vegetales para su confección, es un rubro artesanal menos estudiado; en parte por tratarse de una artesanía que funge como herramienta de trabajo, atributo por el cual no suele clasificarse como artesanía. Esto es lo que ocurre con las jaulas de Tlaltizapán, concebidas como corrales para criar aves -gallinas, codornices- para engorda, venta de huevo o cría de conejo para comercializar su piel. Los artesanos dedicados a esta actividad complementan su ingreso

\footnotetext{
8 En Tlaltizapán, Morelos, en el ejido de Palo Alto, pudimos entrevistar cinco familias dedicadas a la producción de jaulas y persianas, todas están emparentadas entre sí. Hay cada vez más habitantes que recurren a la elaboración de estas artesanías, al grado de que ahora estas jaulas ya forman parte del inventario artesanal del estado y se exhiben en el mMAPO (Museo Morelense de Arte Popular) de Cuernavaca, Morelos.
} 


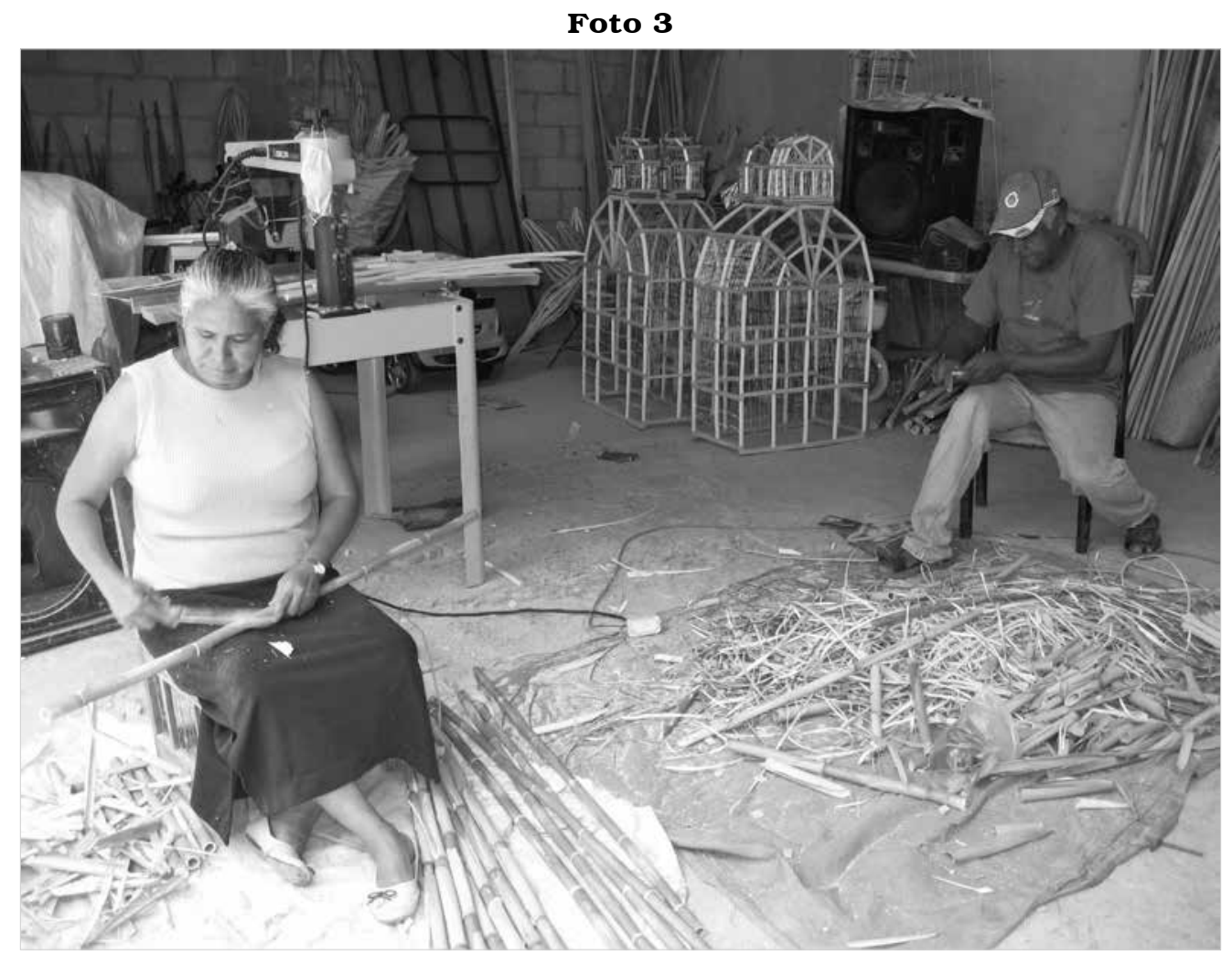

Taller familiar productor de jaulas

elaborando canastos de carrizo, empleados para bajar frutos en huertos y que tienen demanda entre los dueños de quintas y huertos de la región.

Estos artesanos conocen bien el ciclo reproductivo de las plantas y guardan celosamente sus conocimientos de cómo extraer y preparar la materia prima para su confección. Para hacer las jaulas se utiliza el cacaloxóchitl, el cual da una flor aromática que le ha generado el sobrenombre de flor de mayo. Se encuentra en las tierras bajas de Morelos y se extiende a lo largo de carreteras como las que van de Cuernavaca hacia Santa Cruz, Zacatepec, San Miguel Treinta y Xoxocotla, así como en la Mosquitera rumbo a Jojutla.

Hombres y mujeres buscan las varas indicadas (deben ser un poco flexibles, pero no demasiado, si no se rompen); el árbol debe ser joven, porque cuando madura pierde esta flexibilidad y al horadarlo se quiebra. El mejor momento para cortar las varas es después de la época de lluvias, para que no tengan tanta agua y se puedan horadar (de septiembre a diciembre); en este periodo se recolectan las varas y se almacenan para utilizarlas todo el año. De igual manera, el carrizo para los canastos se recolecta en esa temporada y se guarda para la confección de los canastos.

Se trata de una producción que se realiza en el seno del ámbito doméstico y por medio de procesos tales como la impregnación e imitación (Chamoux, 1992), a través de los cuales los hijos adquieren los conocimientos necesarios para dominar todas y cada una de las fases que constituyen el proceso productivo de las jaulas y los canastos.

Braulio Gómez y Josefina Puente son originarios de Yextla, Guerrero, y crecieron en hogares donde sus padres hacían jaulas. Trabajaban esta artesanía y aprendieron las labores del campo. Cuando se casaron siguieron este patrón de ocupación laboral, pero la situación empeoró porque había escasez de tierra para sembrar y la venta de las jaulas disminuyó porque fueron desplazadas por las de origen industrial. Dadas estas circunstancias, aprovecharon la invitación de ir a la feria de Tepalcingo, Morelos para ofertar sus artesanías; durante el camino se percataron de que había muchos árboles de cacaloxóchitl e innumerables huertas donde sin dificultad les comprarían sus canastos de carrizo.

Estas ventajas los llevaron a decidir mudarse al ejido de Palo Alto, Tlaltizapán, donde sus hijos, José y Rafael, contrajeron matrimonio con chicas de familias de esta población y empezaron a enseñarles a hacer jaulas y canastos a sus parientes afines-cuñadas(os), suegros, primas(os), amigos-, de modo que ahora varios hogares trabajan ya jaulas y canastos. 


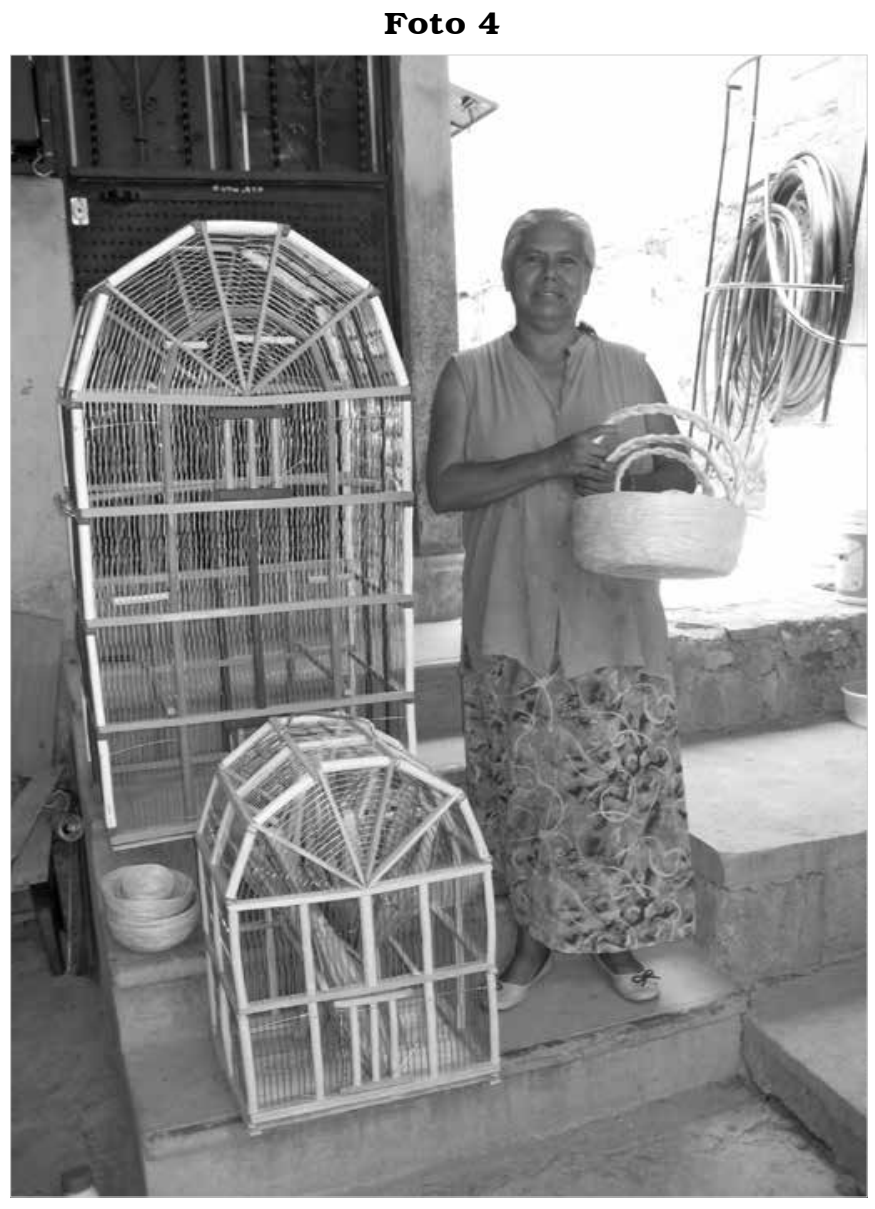

Artesanías de jarciería de Palo Alto, Tlaltizapán

Más tarde Braulio y Josefina obtuvieron apoyo de instancias promotoras de las artesanías -el Programa de Apoyo a las Culturas Municipales y Comunitarias, PACMYC, y el Fondo Nacional de Apoyo para las Empresas en Solidaridad, Fonaes ${ }^{9}$ básicamente para compra de maquinaria, y les hicieron pedidos de jaulas, pero solicitándoles que las hicieran decoradas para promocionar con turistas. Fue así como empezaron a pintar las jaulas en vivos colores, sus hijos inventaron nuevas bases -formas prismáticas octagonales, de rombo, hexagonales- y distintos acabados de pintura.

De modo que las jaulas fueron adquiriendo atributos decorativos y llegaron a venderse con éxito en ferias artesanales en distintos sitios de la república (Guanajuato, Jalisco y Estado de México) y de unos cinco años a la fecha en las tiendas de artesanías de los aeropuertos en el país y en sitios turísticos de la entidad como Tepoztlán, Cuernavaca, Tlayacapan, Oaxtepec, Cuautla; también en Acapulco y Taxco, Guerrero, y en ferias de Atlatlahucan, Tepalcingo y Mazatepec. Ade- más, ahora tienen pedidos de zoológicos, restaurantes, museos y hoteles, que piden las jaulas con distintos acabados, fase decorativa que recae en manos de las mujeres, y complementan esta tarea haciendo canastos y nidos de ixtle (extraído de una cactácea que crece en las inmediaciones de Palo Alto). Incluso en algunos viveros visitados por turistas es usual que las jaulas se comercialicen como envoltura para regalar alguna planta y, como dice Josefina, "entre más colorida, a la gente se le hace más mexicano”.

Algunos intermediarios compran jaulas para diseñar su interior con alguna escenificación asociada a lo "mexicanamente representativo" -por ejemplo un altar a la Virgen de Guadalupe o algún personaje famoso, Diego de Rivera o Frida Kahlo, entre otros, o bien imágenes alusivas a la celebración de los fieles difuntos, Navidad o las fiestas patrias-, escenificaciones decorativas para las cuales utilizan otras artesanías miniaturas, explotando aún más esta idea de representar lo "auténticamente mexicano".

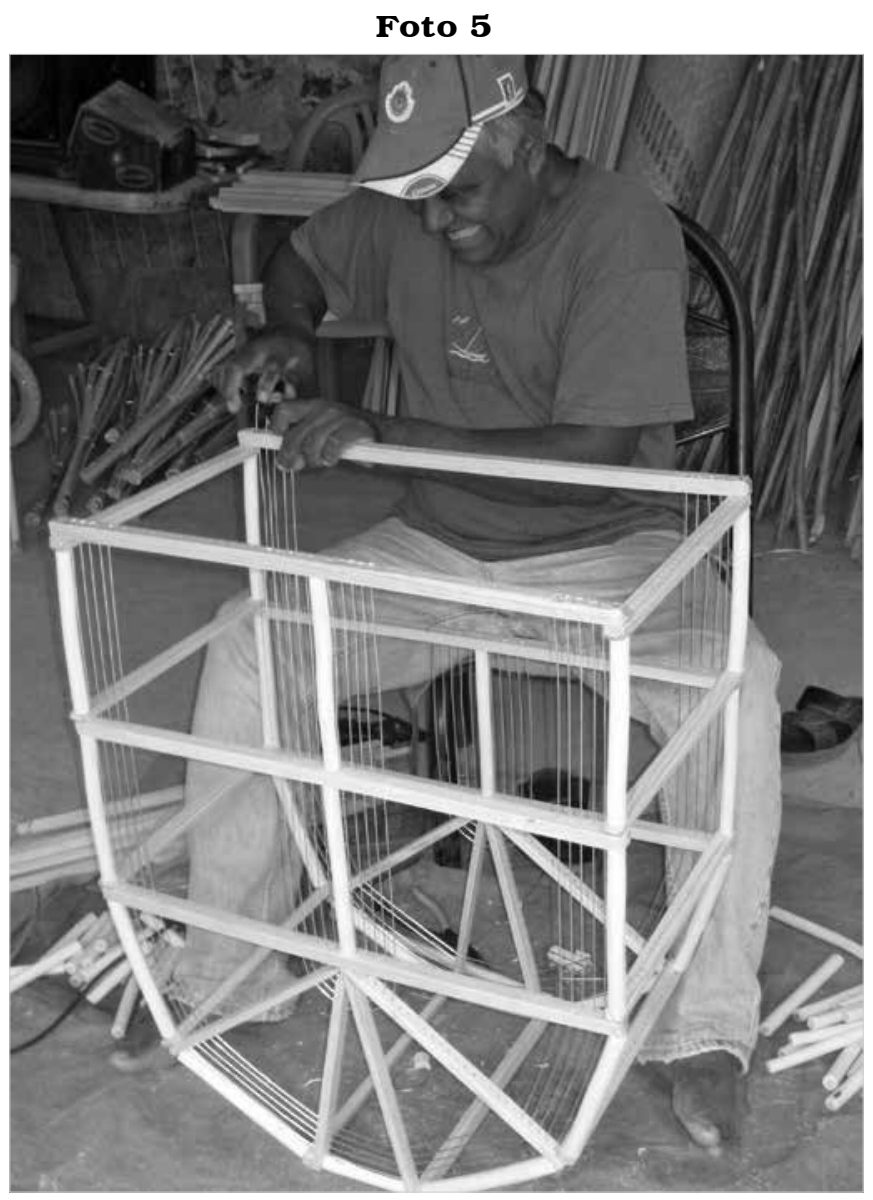

Confección de jaula, especialización masculina

9 Incluso en ocasiones la Secretaría de la Defensa Nacional (Sedena) les ha prestado camiones para trasladarse a las ferias artesanales. 
Otra modalidad es decorar el interior de las jaulas para algún festejo vinculado al ciclo vital reproductivo o rituales de pasaje -quince años, despedida de soltera, bodas, baby shower, bautizo, primera comunión-; dentro se colocan los recuerdos alusivos al acto o bien se almacenan las cuotas de recuperación de los invitados.

Fue por este valor decorativo que las jaulas se integraron a un nuevo circuito comercial, para ser consumidas por nuevos sectores del ámbito rural campesino; suscitándose el surgimiento de un objeto que ya no es sólo un producto o una mercancía, sino también un símbolo dentro de un sistema de signos de estatus sociales (Spooner, 1991).

En esta desviación productiva y comercial, a diferencia del caso de la loza de Tlayacapan, no se observó un cambio sustancial en la técnica de las fases que integran la manufactura, simplemente se anexaron etapas de decorado y el objeto conservó en esencia su estructura. En términos metafóricos podemos decir que la jaula experimentó un proceso de metamorfosis en el cual, sin dejar de ser lo que era en sus orígenes, esto es, una jaula para contener algo (en principio animales de corral), sólo se remozó su apariencia para darle el mismo uso de resguardar, pero ahora objetos o animales exóticos (tucanes, pericos, loros) o plantas.

Desde un punto de vista tecnológico, tampoco hubo mayor innovación en la organización del trabajo; el padre se mantuvo como jefe y maestro del oficio, las mujeres se concentraron en el decorado y el varón es quien las arma, pues esta tarea requiere para mayor fuerza física.

Este ejemplo nos muestra cómo, para no sucumbir las tradiciones artesanales deben abandonar ciertas pertenencias socioculturales en las que se imbricó su origen, llámese pertenencia territorial, étnica, laboral o familiar. Se trata de una reinvención del oficio, que revela cómo la herencia del mismo debe acoplarse a las condiciones socioeconómicas y culturales del contexto actual para prevalecer.

\section{Reflexiones finales}

Como fue posible apreciar, ambos casos coinciden en haber dado un giro productivo y comercial a artesanías decorativas para venderse al turismo, pero el modelo familiar patriarcal se mantuvo como infraestructura del trabajo, aunque de manera distinta: en el caso de las jaulas de Palo Alto se ratificó la figura del padre y los hijos casados se van integrando al taller del padre hasta independizarse. En cambio, en Tlayacapan, la figura paterna y la interdependencia entre hijos y hermanos se aminoró y favoreció la independencia de sus talleres, pues la cerámica decorativa requiere menos orquestación en manos de un sujeto (padre).

A partir del estudio de la cultura material, González plantea que la historia de las relaciones sociales en torno a la herencia obliga a la dinámica del posicionamiento social de los actores; es decir, cuando se hacía loza, el padre fungía como jefe del taller, mientras que con la cerámica suntuaria su papel como tal se desdibujó; esto pone de manifiesto cómo las tradiciones son dinámicas por ser expresiones estéticas y estar sujetas a la moda del consumo: ahora el turismo (González, 2010).

Aunado a lo anterior, el haber promovido a Tlayacapan como pueblo mágico colocó a la loza tradicional como parte del patrimonio cultural; apreciación por cierto desconocida para los alfareros, quienes valoran estos cazos y cazuelas por el papel que desempeñan en su tradición culinaria, misma que refuerza su identidad y favorece la cohesión social. La publicidad de pueblo mágico utiliza como emblema a la loza tradicional en sus trípticos promocionales, pero, de manera absurda, los turistas no la compran, sólo adquieren cerámica decorativa. Así, vemos que los proyectos enfocados a fortalecer el patrimonio cultural y las tradiciones ocupacionales de los pueblos, motivados por intereses políticos, económicos, culturales, entre otros, inherentemente favorecen procesos contradictorios a sus propósitos y desmantelan las tradiciones.

Otra observación resultante de este análisis comparativo sobre la desviación comercial en estas tradiciones artesanas es que la unidad doméstica se preservó como base organizativa; pero los cambios de ideología entre los jóvenes están propiciando una valoración distinta de dicha unidad; prueba de ello es que ahora prefieren la residencia neolocal (vivir aparte de los padres del esposo), en lugar de la patrilocal, como dicta la costumbre, lo cual está repercutiendo en la socialización del individuo en cuanto artesano y en la herencia del oficio.

Por otra parte, cuando se efectúa la desviación comercial de la artesanía hacia objetos suntuarios se deslinda a la alfarería de sus tradicionales atributos de significación, es decir, del papel que tienen los enseres tradicionales en la estética culinaria campesina, la cual, a su vez, nutre la vida comunitaria, fincada en pertenencias socioculturales tales como la etnia o el territorio; tan es así que ahora los cazos y cazuelas de Tlayacapan figuran ya como piezas de museo (en el Museo de la Cerería del pueblo), representando la historia vernácula tlayacapense y, de paso, perdiendo todo el contexto sociocultural de su génesis en cuanto tradición culinaria. 
En contraparte, la desviación comercial de las jaulas hacia objetos decorativos fue lo que permitió salvaguardar su existencia, su técnica se expandió y llegó a nuevas arenas de comercialización; incluso como objeto que emula una expresión de arte, si bien de estética "kitsch mexicano", pero con buena demanda entre el turismo. Las jaulas siguen siendo contenedores de objetos, pero ahora tienen nuevas significaciones; por ejemplo, siendo una jaula se puede asociar a un ave, y de ahí a la cualidad de volar, o referirse a lo etéreo, lo celeste o lo suprahumano. Se trata de atributos de significación relevantes en el contexto de la globalización, promotor del intercambio cultural, que trae consigo "la interculturalidad", y suscitará negociaciones, intercambios y préstamos de uso y significado, donde, además, el consumo cultural abarcará otras ideologías y clases sociales (García Canclini, 2007; González, 2010; Kopytoff, 1991; Spooner, 1991).

\section{Bibliografía}

Appadurai, ArJun (ED.)

1986 La vida social de las cosas, perspectiva cultural de las mercancías, Consejo Nacional para la Cultura y las Artes/Grijalbo, México.

Arias, Patricia

2009 Del arraigo a la diáspora. Dilemas de la familia rural, Miguel Ángel Porrúa/Centro Universitario de Ciencias Sociales y Humanidades-Universidad de Guadalajara, México.

BARTRA, Eli (COMP.)

2004 Creatividad invisible. Mujeres y arte popular en América Latina y el Caribe, Programa Universitario de Estudios de Género-Universidad Nacional Autónoma de México, México.

Chamoux, Marie Nöelle

1992 Trabajo, técnicas y aprendizaje en el México indígena, Centro de Investigaciones y Estudios

DEAN, ARNOLD Superiores en Antropología Social, México.

1988 Ceramic Theory and Cultural Process, Cambridge University Press, Cambridge.

García Canclini, Néstor

2007 "De cómo la interculturalidad global debilita al relativismo", en Angela Giglia, Carlos Garma y Ana Paula de Teresa (comps.), ¿A dónde va la antropología?, Universidad Autónoma Metropolitana, México, pp. 39-59.
González, Alejandro

2010 "La vida social de los objetos etnográficos y su desalmada mercantilización", en Alteridades, año 20, núm. 40, julio-diciembre, pp. 65-76.

KAPLAN, Flora S.

1980 Una tradición alfarera, Instituto Nacional Indigenista, México.

KOPYTOFF, IGOR

1991 "La biografía cultural de las cosas: la mercantilización como proceso", en Arjun Appadurai (ed.), La vida social de las cosas, perspectiva cultural de las mercancías, Consejo Nacional para la Cultura y las Artes/Grijalbo, México, pp. 89-125.

LÉvi-Strauss, Claude

1986 La alfarera celosa, Ediciones Paidós Básica, Barcelona.

Moctezuma, Patricia

2010 "El oficio alfarero de Tlayacapan, Morelos: un legado familiar de saberes técnicos y organizativos", en Relaciones. Estudios de Historia y Sociedad, vol. XXXI, núm. 121, pp. 227-253.

Moctezuma, Patricia

2015 "Mujer, arte popular y cosmogonía", en Eli Bartra y María Guadalupe Huacuz (coords.), Mujeres, feminismo y arte popular, Universidad Autónoma Metropolitana, México, pp. 59-75.

NAROSKY, SUSANA

1988 Trabajar enfamilia. Mujeres, hogares y talleres, Edicions Alfons el Magnànim, Valencia.

Novelo, Victoria (COMP.)

1996 Artesanos, artesanías y arte popular de México, Consejo Nacional para la Cultura y las Artes, México.

Oliva Mendoza, Carlos (comp.)

2009 Figuras. Estética y fenomenología en Hegel, Facultad de Filosofía y Letras-Programa de Maestría y Doctorado en Filosofía, Universidad Nacional Autónoma de México, México.

Ramírez Garayzar, Amalia

2014 Tejiendola identidad: el rebozo entre las mujeres purépechas de Michoacán, Consejo Nacional para la Cultura y las Artes, México.

Rubín de la Borbolla, Daniel

1971 "Los objetos de la vida diaria", en Lo efímero $y$ eterno del arte popular mexicano, Fondo Editorial de la Plástica Mexicana, México.

SennetT, Richard

2009 El artesano, Anagrama, Barcelona.

SPOONER, BRIAN

1991 "Tejedores y comerciantes: la autenticidad de una alfombra oriental", en Arjun Appadurai (ed.), La vida social de las cosas, perspectiva cultural de las mercancías, Consejo Nacional para la Cultura y las Artes/Grijalbo, México, pp. 243-293. 